\title{
Prevalence of papillomavirus infection in women in Ibadan, Nigeria: a population-based study
}

\section{JO Thomas', R Herrero², AA Omigbodun', K Ojemakinde', IO Ajayi ${ }^{3}$, A Fawole', O Oladepo', JS Smith ${ }^{4,6}$, A Arslan ${ }^{4}$, N Muñoz ${ }^{4}$, PJF Snijders ${ }^{5}$, CJLM Meijer ${ }^{5}$ and S Franceschi, ${ }^{*}, 4$}

'College of Medicine, University of Ibadan, PMB 50 17, GPO, Ibadan, Nigeria; ${ }^{2}$ Proyecto Epidemiologico Guanacaste, Costa Rican Foundation for Health Sciences, PO Box 125-6I 5 I, San José, Costa Rica; ${ }^{3}$ General Outpatient Department, University College Hospital, Ibadan, Nigeria; ${ }^{4}$ International Agency for Research on Cancer, 150, cours Albert Thomas, 69008, France; ${ }^{5}$ Department of Pathology, Vrije Universiteit Medical Center, Postbus 7057, NL- 007 MB Amsterdam, The Netherlands

To investigate the prevalence of and the risk factors for cervical infection with human papillomavirus (HPV) in an inner-city area of Ibadan, Nigeria, we interviewed and obtained a sample of cervical cells from 932 sexually active women aged I5 years or older. A total of 32 different HPV types were identified with an HPV prevalence of $26.3 \%$ overall and $24.8 \%$ among women without cervical lesions; or age-standardised to the world standard population of 28.3 and $27.3 \%$, respectively. High-risk HPV types predominated, most notably HPV 16, 31, 35 and 58. In all, 33.5\% of infections involved more than one HPV type. Unlike most populations studied so far, HPV prevalence was high not only among young women, but also in middle and old age. Single women (odds ratio, OR $=2.1$; 95\% confidence interval, $\mathrm{Cl}=1.1-3.9)$ and illiterate women $(\mathrm{OR}=1.7 ; 95 \% \mathrm{Cl}=1.1-2.5)$ showed increased HPV positivity. Associations were also found with anti-Herpes simplex-2 antibodies $(\mathrm{OR}=1.6 ; 95 \% \mathrm{Cl}: \mathrm{I} . \mathrm{I}-2 . \mathrm{I})$ and with the husband's extramarital relationships ( $\mathrm{OR}=1.6: 95 \% \mathrm{Cl}: 1.0-2.6)$. High prevalence of HPV in all age groups may be a distinctive feature of populations where HPV transmission continues into middle age and cervical cancer incidence is very high.

British Journal of Cancer (2004) 90, 638-645. doi:I0.I038/sj.bjc.660I 5 I 5 www.bjcancer.com

(c) 2004 Cancer Research UK

Keywords: human papillomavirus; age; sexual habits; education; kola-nut

The prevalence of cervical infection with human papillomavirus (HPV), particularly of high-risk (HR) types that cause cervical cancer (Muñoz et al, 2003), varies greatly worldwide. A series of population-based HPV surveys coordinated by the International Agency for Research on Cancer (IARC) has shown a 10-fold variation between some areas in Spain (de Sanjosé et al, 2003) and North Vietnam (Anh et al, 2003), where HPV prevalence in sexually active women aged $15-65$ years was below $2 \%$, and areas in Colombia (Molano et al, 2002) and Argentina (Matos et al, $2003)$, where it was $15 \%$ or greater. The prevalence of HR HPV types in middle-aged women and the incidence of cervical cancer in the same age group were strongly positively correlated (Franceschi et al, 2003a).

The incidence of cervical cancer in sub-Saharan Africa is among the highest worldwide, with age-standardised rates of 35.7 per 100000 in Bamako, Mali, and 41.7 per 100000 in Kyadondo, Uganda (Parkin et al, 2002), yet only recently has information on the prevalence of cervical HPV infection become available (Serwadda et al, 1999; Castellsague et al, 2001; Gravitt et al, 2002; De Vuyst et al, 2003; Xi et al, 2003).

Nigeria is the most populous country in Sub-Saharan Africa, with approximately 117 million inhabitants, a life expectancy at

*Correspondence: Dr S Franceschi; E-mail: franceschi@iarc.fr

${ }^{6}$ Formerly of the International Agency for Research on Cancer

Received I5 August 2003; revised 22 October 2003; accepted 27

October 2003 birth of 50.6 years in men and 52.6 years in women, child mortality of 159 and 152 per 1000 in males and females, respectively, and per capita total expenditure on health of US $\$ 8$ per year (http:// www.who.int). The annual age-standardised incidence of cervical cancer in Ibadan in 1998-1999 was 19.9 per 100000 (Parkin et al, 2003).

Here, we report the first study from Nigeria of the prevalence of cervical HPV infection.

\section{MATERIALS AND METHODS}

\section{Study subjects}

A survey was carried out in April and May 1999 enumerating the female population of the Idikan community, an inner-city, densely populated area of Ibadan north west local government area, consisting mainly of Muslim people of low socioeconomic level. A total of 2870 women aged 15 years or older were estimated to live in Idikan. After meetings with community representatives, women were contacted up to three times at their home by four female nurses and asked to come to the Idikan Clinic that is run by the Preventive and Social Medicine Department of the University of Ibadan. According to the exclusion criteria of the protocol of IARC HPV surveys, women who: (1) were pregnant; (2) had undergone hysterectomy or conisation; and (3) were physically or mentally unable to undergo an interview and a pelvic examination were not invited to participate in the present study. 
Between June 1999 and April 2000, 1390 women (48.4\% of those who had been enumerated) came to the Idikan Clinic for an interview and a pelvic examination. Participation was higher among women aged 30 years or older $(66.1 \%)$ than among younger women $(31.9 \%)$ on account of the exclusion of pregnant women and low compliance of nonsexually active women. We therefore excluded from the present report 62 self-reported virgins. Furthermore, 14 women who had moved away from Idikan, 36 who refused a pelvic examination, and, despite exclusion criteria, 47 women who were pregnant, six who had been hysterectomised, and 22 women who were physically unable to undergo pelvic examination were also excluded.

The interview was administered in the local language (Yoruba) by four research nurses. The structured questionnaire, similar to the other HPV survey coordinated by IARC (Shin et al, 2003), included information on sociodemographic characteristics, smoking and chewing habits, reproductive and menstrual factors, sexual habits of the woman and her husband, and lifetime use of contraceptive methods.

All participants signed informed consent forms according to the recommendations of the IARC and local ethical review committees that had approved the study. When indicated, participating women were treated for minor ailments and given multivitamin supplements.

\section{Gynaecological examination and specimen collection}

A total of 1203 sexually active women underwent a pelvic examination by one of the four female nurses. In order to evaluate the feasibility and validity of different screening methods in Nigeria, two different types of tests were performed: Papanicolau (Pap) smear and visual inspection with acetic acid (VIA). In addition, samples of exfoliated cells from the ectocervix and from the endocervix were collected with two Ayre spatulae and a cytobrush (Cervibrush, CellPath). After the preparation of a Pap smear, the remaining exfoliated cervical cells were placed in $50 \mathrm{ml}$ conic tubes that contained $20 \mathrm{ml}$ of phosphate-buffered saline (PBS). All samples were stored in iceboxes and sent daily to the laboratory of the Pathology Department of the University College Hospital, Ibadan, for processing and storage. Samples of exfoliated cells were centrifuged at $3000 \mathrm{~g}$ and the resulting pellet was diluted in $1 \mathrm{ml}$ of PBS and poured into labelled tubes. All samples were stored at $-20^{\circ} \mathrm{C}$ until shipment on dry ice to IARC.

After taking the smear, $4 \%$ freshly prepared acetic acid was generously applied on the cervix using soaked cotton wool swabs and a minute after the cervix was examined to evaluate the presence of: (a) faint acetowhite areas; or (b) dense acetowhite areas (Sankaranarayanan et al, 1998).

Participants with abnormal findings at cytological or VIA examination were referred, free of charge, to the Gynaecology Department of the University College Hospital, Ibadan, for colposcopic examination and, if appropriate, biopsy and treatment.

Pap smears were read at the Pathology Department of the University College Hospital, Ibadan, and classified according to the Bethesda system. Pap smear results were used preferentially for study purposes and were available for 1110 women. For 93 additional women, however, a Pap smear was lost (two) or was inadequate (91 women). We, therefore, classified them as abnormal if the VIA had revealed white lesions. Finally, women were also asked to provide $10 \mathrm{ml}$ of blood.

\section{Human papillomavirus and Herpes simplex-2 (HSV-2) detection techniques}

Human papillomavirus DNA test Human papillomavirus testing was performed on exfoliated cervical cells from 1177 sexually active women. To analyse the quality of target DNA for polymerase chain reaction (PCR) testing, cervical specimens were screened with $\beta$-globin gene-specific primers. In total, 245 samples were found to be $\beta$-globin negative and, as a result, valid HPV results were available for 932 women.

Human papillomavirus positivity was assessed by general primer-mediated GP5 + $/ 6+-\mathrm{PCR}$ and by hybridisation of PCR products in an enzyme immunoassay (EIA) using two HPV oligoprobe cocktails that together detect the following $36 \mathrm{HPV}$ types: HPV 6, 11, 16, 18, 26, 31, 33, 34, 35, 39, 40, 42, 43, 44, 45, 51, $52,53,54,55,56,57,58,59,61,66,68,70,71$ (equivalent to CP8061), 72, 73, 81 (equivalent to CP8304), 82 (IS39 and MM4 subtypes), 83 (equivalent to MM7), 84 (equivalent to MM8), and CP 6108. Polymerase chain reaction products that were positive in the EIA were subsequently subjected to further typing by reverse line blot hybridization (RLB). Probes and procedures used for EIA and RLB are described elsewhere (van den Brule et al, 2002). In addition, EIA-negative samples were tested by low-stringency Southern blot analysis of PCR products with a cocktail probe of HPV-specific DNA fragments to assess whether HPV types were present that were not represented in EIA oligoprobe cocktails. None of such types was found. Special precautions were taken to minimise false-positive results in the PCR, as has been described elsewhere (Walboomers et al, 1999).

HR HPV types for this analysis included HPV types 16, 18, 26, $31,33,35,39,45,51,52,53,56,58,59,66,68,73$, and 82 (Muñoz et al, 2003). The group of low-risk (LR) types included all other HPV types. Human papillomavirus infections having more than one HPV type (i.e., multiple HPV infections) were considered as HR if any of the types detected was an HR type.

Herpes simplex-2 plasma antibodies The presence of type-specific plasma IgG antibodies against HSV-2 (anti-HSV-2) was tested using an HSV-2 ELISA assay developed by Focus Technology/ formerly MRL (Cypress, California) (Ribes et al, 2001). All HSV-2 positive findings were confirmed by means of a second test. Valid HSV-2 results were available from 892 women with valid HPV findings.

\section{Statistical analysis}

Odds ratios (ORs) for HPV positivity and corresponding 95\% confidence intervals (CIs) were calculated by means of unconditional, multiple logistic regression equations, adjusted for age $(<25 ; 25-34 ; 35-44 ; 45-54 ; 55-64 ; \geqslant 65$ years). Variables that showed statistically significant associations with HPV positivity in the age-adjusted analyses were included in the same model and evaluated overall and in separated strata by age group, HR and LR HPV types, and multiplicity of infections. The statistical significance of trends for ORs was assessed by considering the categorical variable as a continuous variable in the logistic model.

\section{RESULTS}

Among the 932 women who had a cytological or VIA examination and valid HPV results, 844 (90.6\%) had normal cervical findings. Among the 862 women for whom a Pap smear was available, 19 $(2.2 \%)$ showed atypical squamous cells of undetermined significance (ASCUS), one showed atypical glandular cells of undetermined significance (AGUS), 37 (4.3\%) low-grade intraepithelial lesions, and $15(1.7 \%)$ high-grade intraepithelial lesions. In addition, one in situ and one invasive cervical cancer were detected. Among 70 women who were screened only by means of VIA, $12(17.1 \%)$ had faint white lesions and two $(2.8 \%)$ had dense white lesions. Only nine women reported to have ever had a Pap smear before.

The prevalence of HPV of any type was 26.3, 24.8 and 40.9\%, respectively, among women with normal and abnormal cervical 
findings (Table 1). Human papillomavirus prevalence age-standardised to the world population was $28.3 \%$ overall, and $27.3 \%$ among women without cervical lesions. A total of $82(8.8 \%$ overall, $33.5 \%$ of HPV-positive women) had multiple HPV infections and a total of $385 \mathrm{HPV}$ infections with 32 different HPV types were detected. High-risk HPV infections were substantially more frequent (19.7\% of all women) than LR HPV infections (6.6\%). The most commonly found HPV types, in either single or multiple infections, were HPV 42 (an LR type, 41 women), HPV 16 (30 women), and HPV 35 ( 30 women), but the type distribution varied by cervical findings. Human papillomavirus 42 was never found in single infections in women with cervical abnormalities. An HR HPV type was found in $34.1 \%$ of women with abnormal cervical findings, and in $18.3 \%$ of those with normal cervical findings. All three women in whom biopsy showed a cervical intraepithelial lesion grade 3 and two women with in situ or invasive cervical carcinomas were HR HPV positive. Combinations of HPV types found in women with multiple HPV infections are given in the appendix.
Figure 1 shows the age pattern of the prevalence of HPV (any type and HR and LR types separately) and that of anti-HSV-2. Anti-HSV-2 was approximately twice as frequent as HPV positivity in any given age group.

Tables 2-4 show the relationship between the HPV positivity and age and the major characteristics of the study women after adjustment for age. Human papillomavirus prevalence was not significantly different in the age groups considered, ranging between $30.8 \%$ among women younger than 25 years and $24.4 \%$ among those in the 55-64 age range (Table 2). Illiteracy, which was reported by $45.7 \%$ of women, was associated with an OR for HPV-positivity of 1.7 (95\% CI: $1.1-2.5)$. Only $1.8 \%$ of the study women had ever smoked cigarettes $(\mathrm{OR}=1.6 ; 95 \% \mathrm{CI}$ : $0.6-4.5$, data not shown), but $35.6 \%$ reported a chewing habit $(\mathrm{OR}=1.4$; $95 \%$ CI: $1.0-1.9$ ). In all, $96 \%$ of chewers chewed kola-nut, while 12 $(3.6 \%)$ chewed a mixture of products that, in three women, included tobacco.

Single women, who accounted for $6.7 \%$ of our study participants, showed an OR of 2.1 (95\% CI: $1.1-3.9)$, whereas no excess

Table I Prevalence of 32 HPV types by findings at cytological smear or VIA and overall among 932 women, Ibadan, Nigeria

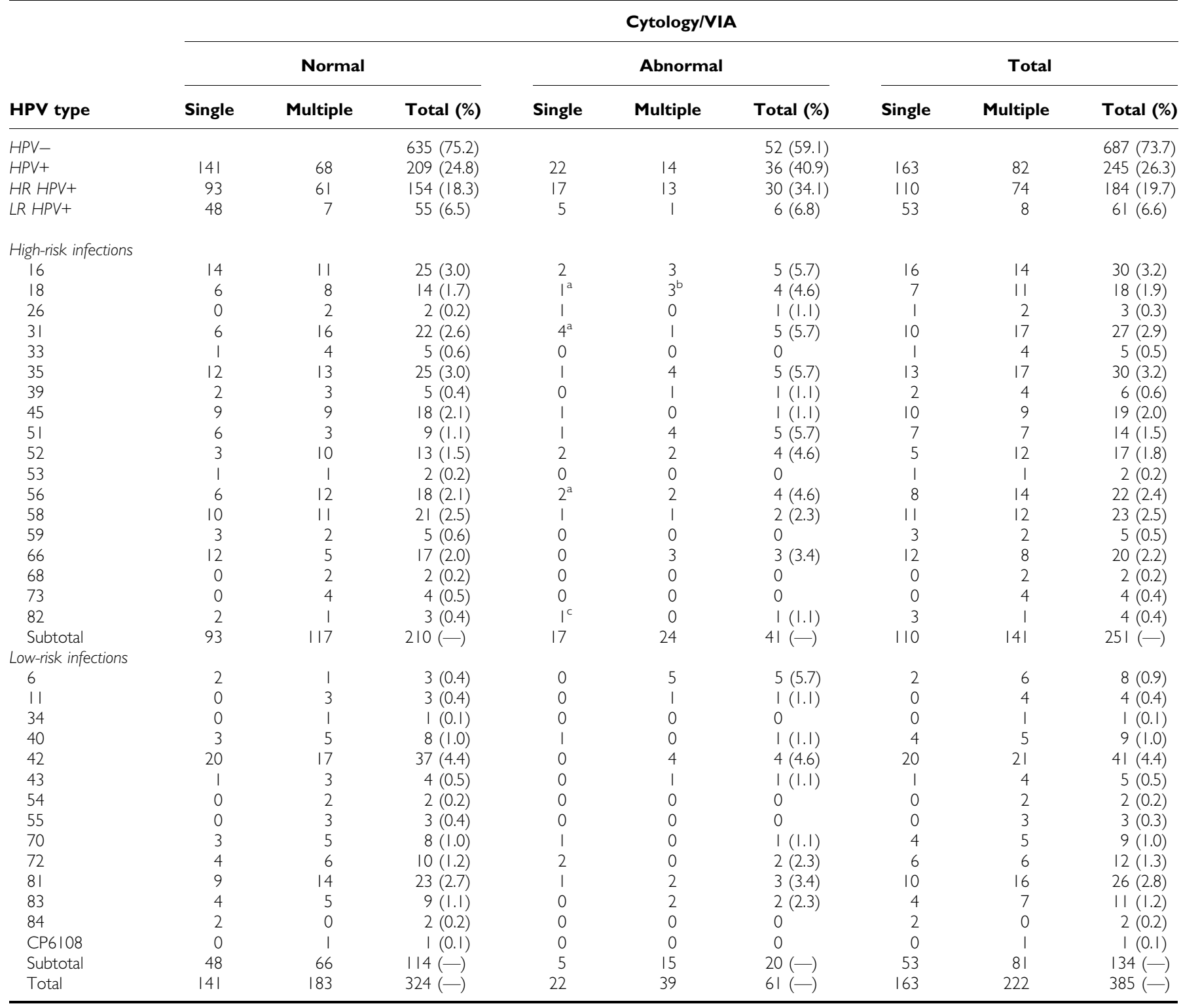

$\mathrm{HPV}=$ human papillomavirus; VIA = visual inspection with acetic acid. ${ }^{a}$ It includes one histologically confirmed cervical intraepithelial neoplasm 3 . 'blt includes one in situ squamous cell carcinoma of the cervix. 'It includes one invasive squamous cell carcinoma of the cervix. 


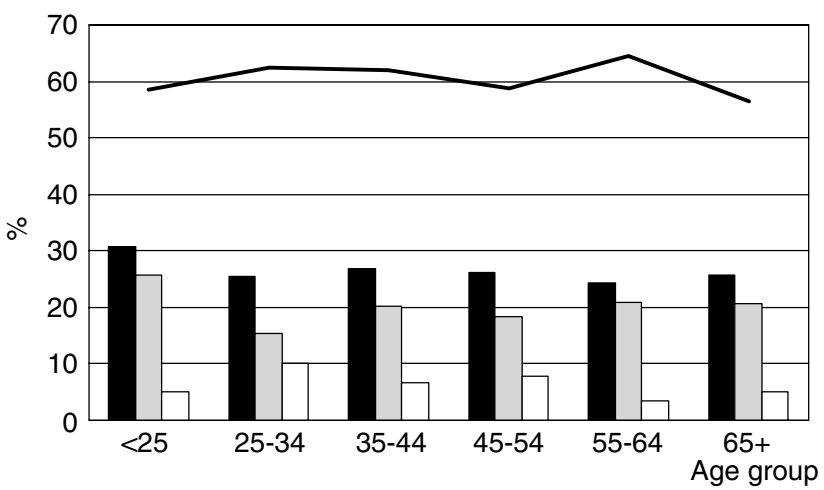

any HPV type $\square$ high-risk HPV

$\square$ low-risk HPV - anti-HSV2

Figure I Age-specific prevalence of HPV and anti-HSV-2 antibodies.

Table 2 Odds ratios (ORs) for HPV positivity and corresponding 95\% confidence intervals (Cls) according to sociodemographic and reproductive characteristics among $932^{\mathrm{a}}$ women, Ibadan, Nigeria

\begin{tabular}{|c|c|c|c|c|c|}
\hline & \multirow[b]{2}{*}{ Number of women } & \multicolumn{2}{|c|}{ HPV positive } & \multirow[b]{2}{*}{$\mathbf{O R}^{\mathbf{b}}$} & \multirow[b]{2}{*}{$95 \% \mathrm{Cl}$} \\
\hline & & $\mathbf{N}$ & (\%) & & \\
\hline \multicolumn{6}{|l|}{ Age (years) } \\
\hline$<25$ & 120 & 37 & $(30.8)$ & 1 & \\
\hline $25-34$ & 189 & 48 & $(25.4)$ & 0.8 & $(0.5-1.3)$ \\
\hline $35-44$ & 134 & 36 & $(26.9)$ & 0.8 & $(0.5-1.4)$ \\
\hline $45-54$ & 196 & 51 & $(26.0)$ & 0.8 & $(0.5-1.3)$ \\
\hline $55-64$ & 172 & 42 & $(24.4)$ & 0.7 & $(0.4-1.2)$ \\
\hline$\geqslant 65$ & 121 & 31 & $(25.6)$ & 0.8 & $(0.4-1.4)$ \\
\hline$\chi_{1}^{2}$ for trend & & & & 0.74 & $P=0.39$ \\
\hline \multicolumn{6}{|l|}{ Education } \\
\hline Primary or better & 495 & 121 & $(24.4)$ & 1 & \\
\hline Illiterate & 417 & 117 & $(28.1)$ & 1.7 & $(1.1-2.5)$ \\
\hline \multicolumn{6}{|l|}{ Chewing habit } \\
\hline No & 600 & 147 & $(24.5)$ & 1 & \\
\hline Yes & 331 & 98 & $(29.6)$ & 1.4 & $(1.0-1.9)$ \\
\hline \multicolumn{6}{|l|}{ Marital status } \\
\hline Married & 687 & 178 & $(25.9)$ & 1 & \\
\hline Single & 62 & 25 & $(40.3)$ & 2.1 & $(1.1-3.9)$ \\
\hline Divorced/widowed & 183 & 42 & $(23.0)$ & 0.8 & $(0.5-1.3)$ \\
\hline \multicolumn{6}{|l|}{ Number of pregnancies } \\
\hline 0 & 57 & 22 & $(38.6)$ & 1.7 & $(0.8-3.4)$ \\
\hline $1-2$ & 134 & 39 & $(29.1)$ & I & \\
\hline $3-4$ & 164 & 45 & $(27.4)$ & 0.8 & $(0.5-1.4)$ \\
\hline $5-6$ & 230 & 49 & $(21.3)$ & 0.6 & $(0.3-1.0)$ \\
\hline$\geqslant 7$ & 326 & 87 & $(26.7)$ & 0.7 & $(0.4-1.3)$ \\
\hline$\chi_{1}^{2}$ for trend & & & & 1.96 & $P=0.16$ \\
\hline \multicolumn{6}{|c|}{ Age at first pregnancy (years) } \\
\hline$\geqslant 25$ & 253 & 69 & $(27.3)$ & 1 & \\
\hline $20-24$ & 479 & 115 & $(24.0)$ & 0.8 & $(0.6-1.2)$ \\
\hline$\leqslant 19$ & 132 & 38 & $(28.8)$ & 1.0 & $(0.6-1.7)$ \\
\hline$\chi_{1}^{2}$ for trend & & & & 0.02 & $P=0.90$ \\
\hline
\end{tabular}

of HPV positivity was found among 43 divorced or 140 widowed women compared to currently married ones. Only $6.3 \%$ of women had never been pregnant, whereas $61.0 \%$ reported five pregnancies or more. Nulligravidae showed, $v s$ women with one or two pregnancies, an OR of 1.7 (95\% CI: $0.8-3.4)$, but the trend in risk by number of pregnancies was not significant. In all, $15.1 \%$ of women reported becoming pregnant for the first time before the age 20 years but age at first pregnancy was not significantly associated with HPV positivity (Table 2). Odds ratios for different number of births were very similar to those for number of pregnancies. The OR for HPV positivity among 356 (38.2\%) women who reported one abortion or more (mainly miscarriages) was 0.9 (95\% CI: 0.7-1.2) (data not shown).

Among indicators of sexual habits (Table 3), age at first intercourse (below 20 years of age in $49.3 \%$ of study women) seemed unrelated to HPV prevalence. Two lifetime sexual partners or more were reported by $47.1 \%$ of the study women and a direct association of borderline statistical significance was found with HPV positivity (OR for three partners or more $v s$ one $=1.4,95 \%$ CI: $0.9-2.0$ ). Regular sexual partners (i.e., male sexual partners in relationships that had lasted at least 6 months) and occasional sexual partners were also evaluated separately (data not shown). The OR for two regular sexual partners or more was $1.2(95 \% \mathrm{CI}$ : $0.9-1.7)$. A history of occasional sexual partners $(19.1 \%$ of study women) was associated with an OR of 1.3 (95\% CI: $0.9-1.8)$. Only $15.6 \%$ of study women believed that that their husbands had not had extramarital sexual relationships. The OR for HPV positivity among those women who were certain about their husbands having had an extramarital sexual relationship was 1.6 (95\% CI: 1.0-2.6). According to the women, such relationships involved sex-workers only in a minority of cases. The presence of anti-HSV$2(61.3 \%$ of women) was associated with an OR of 1.6 (95\% CI: $1.1-2.1$ ). Use of hormonal contraceptives (including 41 women who had used injectable types) and condom was reported by 13.6 and $9.0 \%$ of the study women, respectively, and was unrelated to HPV prevalence. Intrauterine devices were used more frequently than any other contraceptive methods and showed an OR of 1.3, of borderline statistical significance (Table 3 ).

The effect of age group and significant risk factors for HPV positivity in age-adjusted analyses is reassessed in Table 4 by means of multiple logistic regression using all listed variables, overall and separately, in women below and above age 35 years, in HR and LR HPV infections and in single and multiple infections. No significant heterogeneity emerged between the different strata. Among all women, only illiteracy and the presence of anti-HSV-2 retained a significant association in the multivariate analyses. The age pattern of HPV positivity was substantially changed in the multivariate analysis, suggesting that high HPV positivity in older women was accounted for by a greater prevalence of some unfavourable characteristics, chiefly illiteracy, which increased from $5.9 \%$ in women below age 25 years to $87.9 \%$ in those aged 55 years or older.

\section{DISCUSSION}

The prevalence of HPV positivity of $26.3 \%$ found in Ibadan, Nigeria is consistent with previous reports of the elevated prevalence of HPV in women in Sub-Saharan Africa. The age pattern was notable, however, with a modest peak of HPV infections (mainly HR HPV types) among women younger than 25 years and a consistently high prevalence among middle-aged and old women. The prevalence of anti-HSV-2 was also high $(61.3 \%)$, reaching maximal levels already in women below age of 25 years. Being single and illiterate were the main correlates of HPV positivity among study women.

Previous HPV surveys in sub-Saharan Africa have generally shown relatively high HPV prevalence with some variation, 
Table 3 Odds ratios (OR) for HPV positivity and corresponding 95\% confidence intervals (Cls) according to indicators of sexual habits and use of contraceptive methods among 932 women, ${ }^{a}$ Ibadan, Nigeria

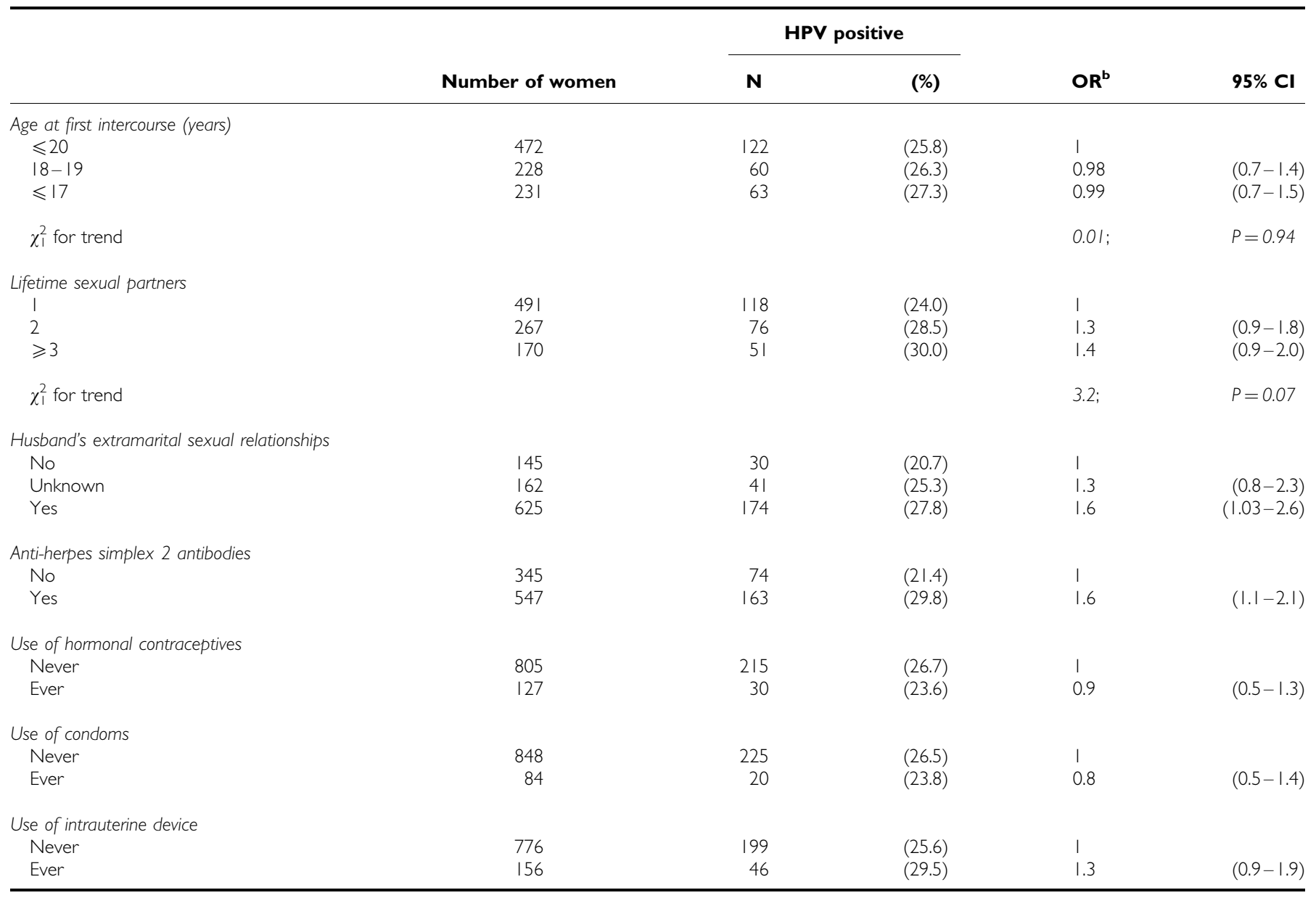

HPV $=$ human papillomavirus. ${ }^{a}$ Some figures do not add up to the total because a few are missing. ${ }^{b}$ Adjusted for age.

depending on how women were selected, and how HPV was tested for. Using the hybrid capture (HC) assay II, a $17 \%$ prevalence of HR HPV types was found in rural Uganda (Serwadda et al, 1999), while a $25 \%$ prevalence was found among HIV-negative women in Harare, Zimbabwe (Womack et al, 2000). Polymerase chain reaction-based assays showed HPV prevalence of $40 \%$ in rural Mozambique (Castellsague et al, 2001), of $31 \%$ in Harare, Zimbabwe (Gravitt et al, 2002), of $18 \%$ in Dakar and Pikene, Senegal (Xi et al, 2003), and of $44 \%$ in Nairobi, Kenya (De Vuyst et al, 2003). As in most previous studies (Castellsague et al, 2001; Gravitt et al, 2002; De Vuyst et al, 2003), we found that multiple HPV infections were involved in a substantial fraction of HPV positive women.

Several authors have raised the possibility of certain HPV types being more common in Sub-Saharan African women than elsewhere. HPV 35, for instance, was slightly more common than HPV 16 in Mozambique both in women with normal cytology and in those with HSIL or worse (Castellsague et al, 2001). HPV 52 was found slightly more frequently than HPV 16 or HPV 35 in Kenya (De Vuyst et al, 2003) and in colposcopically normal women in Zimbabwe (Gravitt et al, 2002). In Senegal, HPV 16 and 58 were the most common types overall and in women with cervical lesions (Xi et al, 2003). In our study, when the frequency of HPV types both in single and multiple infections were combined, HPV 16 and 35 were the most common HR types, followed by HPV 31, 58, and 56. An LR type, HPV 42, was also common.
Several caveats are relevant to the interpretation of variations in HPV type distribution. As noted by Gravitt et al (2002), typespecific HPV prevalence may be influenced by the type of assay used and by the high proportion of multiple HPV infection in certain populations. Furthermore, studies from sub-Saharan Africa have shown variations in the relative ranking of HPV types that are compatible with chance and everywhere the predominance of HPV 16 and 18 rises with the increasing severity of cervical findings (Clifford et al, 2003a,b). The type-specific distribution of HPV among 799 cervical cancer biopsies from Africa showed that HPV 16 accounted for $50.2 \%$ of samples, HPV 18 for $14.1 \%$, and HPV 45 for $7.9 \%$ (i.e., a distribution similar to that found worldwide) (Clifford et al, 2003b).

The age pattern of HPV prevalence also differs somewhat from one country to another. The predominant pattern includes an early peak, soon after the start of sexual intercourse (Jacobs et al, 2000; Kjaer et al, 2001), followed by lower levels of HPV positivity in middle age (Jacobs et al, 2000; Sellors et al, 2000; Molano et al, 2002; Anh et al, 2003; de Sanjosé et al, 2003; Matos et al, 2003; Shin et al, 2003; Sukvirach et al, 2003). U-shaped curves were also found, but the age group with the lowest HPV prevalence was not entirely consistent (e.g., at ages 35-54 years in Costa Rica, (Herrero et al, 2000) and 35-44 years in Mexico (Lazcano-Ponce et al, 2001)). In three studies from sub-Saharan Africa (Serwadda et al, 1999; Castellsague et al, 2001; De Vuyst et al, 2003), the prevalence of HPV declined with age. In one study (Xi et al, 2003) 
Table 4 Odds ratios (ORs) a and corresponding 95\% confidence intervals (Cls) for major risk factors for HPV positivity by age group, HPV type, and multiplicity of infection and overall among 932 women, Ibadan, Nigeria

\begin{tabular}{|c|c|c|c|c|c|c|c|}
\hline & \multicolumn{2}{|c|}{ Age } & \multicolumn{2}{|c|}{ HPV type(s) } & \multicolumn{2}{|c|}{ Multiplicity } & Total \\
\hline$<25$ & 1 & - & 1 & I & 1 & 1 & । \\
\hline $25-34$ & $0.8(0.4-1.3)$ & - & $1.7(0.7-4.6)$ & $0.6(0.3-1.01)$ & $1.0(0.6-1.2)$ & $0.4(0.2-0.9)$ & $0.8(0.5-1.3)$ \\
\hline $35-44$ & - & 1 & $0.9(0.3-2.7)$ & $0.6(0.3-1.1)$ & $0.8(0.4-1.5)$ & $0.5(0.2-1.2)$ & $0.6(0.4-1.1)$ \\
\hline $45-54$ & - & $1.6(0.8-2.9)$ & $0.7(0.2-2.2)$ & $0.5(0.3-0.9)$ & $0.6(0.3-1.1)$ & $0.4(0.2-1.1)$ & $0.5(0.3-0.9)$ \\
\hline \multicolumn{8}{|l|}{ Education } \\
\hline Primary or better & 1 & I & I & 1 & I & 1 & 1 \\
\hline Illiterate & $2.3(0.8-6.5)$ & $1.6(1.02-2.6)$ & $2.1(0.98-4.5)$ & $1.5(0.96-2.5)$ & $1.7(1.01-2.7)$ & $1.6(0.8-3.2)$ & $1.7(1.1-2.5)$ \\
\hline \multicolumn{8}{|l|}{ Chewing habit } \\
\hline No & 1 & 1 & । & । & 1 & I & 1 \\
\hline \multicolumn{8}{|c|}{ Husband's extramarital relationships } \\
\hline \multicolumn{8}{|c|}{ Anti-herpes simplex-2 antibodies } \\
\hline No & 1 & 1 & 1 & 1 & I & I & 1 \\
\hline Yes & I.I (0.7- I.9) & $1.8(1.2-2.6)$ & $1.2(0.7-2.1)$ & $1.6(1.1-2.3)$ & $1.3(0.9-1.9)$ & $2.1(1.2-3.5)$ & $1.5(1.1-2.1)$ \\
\hline
\end{tabular}

$\mathrm{HPV}=$ human papillomavirus. ${ }^{\mathrm{a} D e r i v e d ~ f r o m ~ a ~ m u l t i p l e ~ l o g i s t i c ~ r e g r e s s i o n ~ e q u a t i o n ~ t h a t ~ i n c l u d e d ~ a l l ~ t h e ~ f a c t o r s ~ l i s t e d ~ i n ~ t h e ~ t a b l e s . ~}$

HR, but not LR HPV types, were more frequently detected in older than younger women.

The high prevalence of HPV in middle and old age in Ibadan, Nigeria may have different explanations. A fraction of men and women in Ibadan may continue to have multiple sexual contacts throughout their life and therefore reinfect themselves and their spouses. Women in Ibadan may also have decreased ability to clear HPV infections, possibly due to concomitant genital infections or nutritional deficiencies. We found an age pattern similar to the one in Ibadan in another population at very high-risk for cervical cancer, namely, Chennai, Southern India (Franceschi et al, 2003b). Most of the risk factors for HPV positivity we had identified, notably illiteracy (as an indicator of poverty), chewing, and husbands' extramarital relationships, were more frequent among older than young women.

It is noteworthy that the presence of anti-HSV-2, multiplicity of sexual partners, and husbands' extramarital sexual relationships were common in Ibadan but that the association of these factors with HPV positivity was relatively weak. As noted with respect to male sexual habits in another high-risk area (Colombia) (Muñoz et al, 1996), the effect of variations in individual sexual habits becomes difficult to detect in populations where the background prevalence of sexually transmitted disease exceeds a certain threshold. The number of pregnancies was not significantly associated with HPV positivity. The higher proportion of HPVpositive women among nulligravidae was chiefly due to the fact that $80.7 \%$ of them were single (OR for nulligravidae $v s$ gravidae, adjusted for marital status $=1.0$; $95 \%$ CI: $0.4-2.7$ ). Finally, the habit of chewing was another correlate of HPV positivity in our study. We have previously reported an association between chewing habit and cervical cancer in Southern India, where paan is chiefly composed of betel leaves, areca nut, and tobacco (Rajkumar et al, 2003). In Nigeria, women reported chewing kolanut almost exclusively (Cola nitida and Cola acuminata), which is high in caffeine, and serves as a stimulant (Morton 1992).

The potential limitations of our survey include the relatively high proportion of inadequate cervical cell samples and the low participation rate. The relatively high proportion of $\beta$-globin negativity in the cervical cell samples may be due to problems in the transport or storage of cervical cell samples or to the limited experience of our study nurses in cervical cell collection. High proportions of $\beta$-globin negative samples have been a problem in other IARC surveys in developing countries (Anh et al, 2003; Sukvirach et al, 2003). Cytological findings were missing or inadequate in approximately $10 \%$ of women and were substituted, in order to stratify HPV prevalence by the presence of cervical abnormalities, by VIA findings. Reliance on VIA, which is known to be less specific than Pap smear (Sankaranarayanan et al, 1998), was, however, necessary in fewer than 100 women. Their exclusion would have not altered our findings on HPV prevalence by the presence of cervical lesions. Problems with the preparation, and the classification of Pap smears may explain the relatively low proportion of HPV positivity among women with cervical abnormalities but would not affect our conclusions overall.

With respect to the 390 eligible women who were interviewed but for whom information on HPV or cervical status could not be obtained on account of various technical problems, their distribution by sexual and nonsexual factors was similar to that of women who were included in our final analyses, thus weighing against a clear selection bias. It is also reassuring that the distribution of some of the characteristics investigated (e.g., multiple sexual partners, parity, use of OCs or condoms) was consistent with those reported nationwide by publications of the World Health Organization (http://www.who.int).

Finally, we did not have information on HIV status. The most recent findings from HIV Surveillance in Ibadan showed an HIV prevalence of $3.3 \%$ among pregnant women in 2001, $22.6 \%$ among female sex workers in 1995 , and $6.2 \%$ among patients of sexually transmitted disease clinics in 1993 (http:// www.unaids.org). Peak infection occurred among women less than 30 years and would, therefore, not explain the high HPV prevalence we found among women of middle and old age. 


\section{ACKNOWLEDGEMENTS}

We thank Dr Rhoda Ashley, University of Washington, Seattle, US, for testing for anti-HSV-2 antibodies and useful comments, Dr Sankaranarayanan from IARC, Lyon, France, for advice on the performance of VIA, and Jolein Pleijster, Vrije Universiteit Medical
Center, Amsterdam, the Netherlands, for help with HPV testing. We are also grateful to the nurses of the Department of Preventive and Social Medicine and the technical staff of the Pathology Department, Ibadan.

\section{REFERENCES}

Anh PT, Hieu NT, Herrero R, Vaccarella S, Smith JS, Thuy NT, Nga NH, Duc NB, Ashley R, Snijders PJ, Meijer CJ, Muñoz N, Parkin DM, Franceschi S (2003) Human papillomavirus infection among women in South and North Vietnam. Int J Cancer 104: $213-220$

Castellsague X, Menendez C, Loscertales MP, Kornegay JR, dos Santos F, Gomez-Olive FX, Lloveras B, Abarca N, Vaz N, Barreto A, Bosch FX, Alonso P (2001) Human papillomavirus genotypes in rural Mozambique. Lancet 358: $1429-1430$

Clifford GM, Smith JS, Aguado T, Franceschi S (2003a) Comparison of HPV type distribution in high-grade cervical lesions and cervical cancer: a meta-analysis. Br J Cancer 89: $101-105$

Clifford GM, Smith IS, Plummer M, Muñoz N, Franceschi S (2003b) Human papillomavirus types in invasive cervical cancer worldwide: a metaanalysis. Br J Cancer 88: 63-73

de Sanjosé S, Almirall R, Lloveras B, Font R, Diaz M, Muñoz N, Catala I, Meijer CJ, Snijders PJ, Herrero R, Bosch FX (2003) Cervical human papillomavirus infection in the female population in Barcelona, Spain. Sex Transm Dis 30: $788-793$

De Vuyst H, Steyaert S, Van Renterghem L, Claeys P, Muchiri L, Sitati S, Vansteelandt S, Quint W, Kleter B, Van Marck E, Temmerman M (2003) Distribution of human papillomavirus in a family planning population in Nairobi, Kenya. Sex Transm Dis 30: 137-142

Franceschi S, Clifford GM, Vaccarella S, Shin HR, Sukvirach S, Anh PT, Matos E, Molano M, Thomas J, Herrero R (2003a) Geographic variation in HPV infection. In: Monsonego J (ed) Fifth International Multidisciplinary Congress Eurogin 2003. Paris, France, 13-16 April. Bologna: Monduzzi Editore pp 35-40

Franceschi S, Rajkumar T, Vaccarella S, Gajalakshmi V, Sharmila A, Snijders PJ, Muñoz N, Meijer CJ, Herrero R (2003b) Human papillomavirus and risk factors for cervical cancer in Chennai, India: a case-control study. Int J Cancer 107: 127-133

Gravitt PE, Kamath AM, Gaffikin L, Chirenje ZM, Womack S, Shah KV (2002) Human papillomavirus genotype prevalence in high-grade squamous intraepithelial lesions and colposcopically normal women from Zimbabwe. Int J Cancer 100: 729-732

Herrero R, Hildesheim A, Bratti C, Sherman ME, Hutchinson M, Morales J, Balmaceda I, Greenberg MD, Alfaro M, Burk RD, Wacholder S, Plummer M, Schiffman M (2000) Population-based study of human papillomavirus infection and cervical neoplasia in rural Costa Rica. J Natl Cancer Inst 92: $464-474$

Jacobs MV, Walboomers JM, Snijders PJ, Voorhorst FJ, Verheijen RH, Fransen-Daalmeijer N, Meijer CJ (2000) Distribution of 37 mucosotropic HPV types in women with cytologically normal cervical smears: the agerelated patterns for high-risk and low-risk types. Int J Cancer 87: $221-227$

Kjaer SK, Chackerian B, van den Brule AJ, Svare EI, Paull G, Walbomers JM, Schiller JT, Bock JE, Sherman ME, Lowy DR, Meijer CL (2001) Highrisk human papillomavirus is sexually transmitted: evidence from a follow-up study of virgins starting sexual activity (intercourse). Cancer Epidemiol Biomarkers Prev 10: $101-106$

Lazcano-Ponce E, Herrero R, Muñoz N, Cruz A, Shah KV, Alonso P, Hernandez P, Salmeron J, Hernandez M (2001) Epidemiology of HPV infection among Mexican women with normal cervical cytology. Int $J$ Cancer 91: $412-420$

Matos E, Loria D, Amestoy G, Herrera L, Prince MA, Moreno J, Krunfly C, van den Brule AJ, Meijer CJ, Muñoz N, Herrero R, Proyecto Concordia Collaborative Group (2003) Prevalence of human papillomavirus (HPV) infection among women in Concordia, Argentina: a population-based study. Sex Transm Dis 30: 593-599

Molano M, Posso H, Weiderpass E, van den Brule AJ, Ronderos M, Franceschi S, Meijer CJ, Arslan A, Muñoz N (2002) Prevalence and determinants of HPV infection among Colombian women with normal cytology. Br J Cancer 87: 324-333
Morton JF (1992) Widespread tannin intake via stimulants and masticatories, especially guarana, kola nut, betel vine, and accessories. Basic Life Sci 59: $739-765$

Muñoz N, Bosch FX, de Sanjose S, Herrero R, Castellsague X, Shah KV, Snijders PJ, Meijer CJ (2003) Epidemiologic classification of human papillomavirus types associated with cervical cancer. $N$ Engl J Med 348: $518-527$

Muñoz N, Castellsague X, Bosch FX, Tafur L, de Sanjose S, Aristizabal N, Ghaffari AM, Shah KV (1996) Difficulty in elucidating the male role in cervical cancer in Colombia, a high-risk area for the disease. $J$ Nat Cancer Inst 88: $1068-1075$

Parkin DM, Ferlay J, Hamdi-Cherif M, Sitas F, Thomas JO, Wabinga H, Whelan SL. (2003) Cancer in Africa: Epidemiology and Prevention. 4.3 Cervix Cancer. IARC Scientific Publications No 153. Lyon: IARC Press pp $268-276$

Parkin DM, Whelan SL, Ferlay J, Thomas DB, Teppo L (2002) Cancer Incidence in Five Continents. IARC Scientific Publications No 155, Lyon: International Agency for Research on Cancer

Rajkumar T, Franceschi S, Vaccarella S, Gajalakshmi V, Sharmila A, Snijders PJ, Muñoz N, Meijer CJ, Herrero R (2003) Role of paan chewing and dietary habits in cervical carcinoma in Chennai, India. Br J Cancer 88: $1388-1393$

Ribes JA, Hayes M, Smith A, Winters JL, Baker DJ (2001) Comparative performance of herpes simplex virus type 2-specific serologic assays from meridian diagnostics and MRL diagnostics. J Clin Microbiol 39: $3740-3742$

Sankaranarayanan R, Wesley R, Somanathan D, Dhakad N, Shyamalakumary B, Sreedevi Amma N, Parkin DM, Krishnan Nair M (1998) Performance of visual inspection after acetic acid application (VIA) in the detection of cervical cancer precursors. Cancer 83: 2150-2156

Sellors JW, Mahony JB, Kaczorowski J, Lytwyn A, Bangura H, Chong S, Lorincz A, Dalby DM, Janjusevic V, Keller JL (2000) Prevalence and predictors of human papillomavirus infection in women in Ontario, Canada. survey of HPV in Ontario women (SHOW) group. Can Med Assoc J 163: 503-508

Serwadda D, Wawer MJ, Shah KV, Sewankambo NK, Daniel R, Li C, Lorincz A, Meehan MP, Wabwire-Mangen F, Gray RH (1999) Use of a hybrid capture assay of self-collected vaginal swabs in rural Uganda for detection of human papillomavirus. J Infect Dis 180: 1316-1319

Shin HR, Lee DH, Herrero R, Smith JS, Vaccarella S, Hong SH, Jung KY, Kim HH, Park UD, Cha HS, Park S, Touze A, Muñoz N, Snijders PJ, Meijer CJ, Coursaget P, Franceschi S (2003) Prevalence of human papillomavirus infection in women in Busan, South Korea. Int J Cancer 103: $413-421$

Sukvirach S, Smith JS, Tunsakul S, Muñoz N, Kesararat V, Opasatian O, Chichareon S, Kaenploy V, Ashley R, Meijer CJ, Snijders PJ, Coursaget P, Franceschi S, Herrero R (2003) Population-based human papillomavirus prevalence in Lampang and Songkla, Thailand. J Infect Dis 187: 12461256

van den Brule AJ, Pol R, Fransen-Daalmeijer N, Schouls LM, Meijer CJ, Snijders PJ (2002) GP5+/6+ PCR followed by reverse line blot analysis enables rapid and high-throughput identification of human papillomavirus genotypes. J Clin Microbiol 40: 779-787

Walboomers JM, Jacobs MV, Manos MM, Bosch FX, Kummer JA, Shah KV, Snijders PJ, Peto J, Meijer CJ, Muñoz N (1999) Human papillomavirus is a necessary cause of invasive cervical cancer worldwide. J Pathol 189: $12-19$

Womack SD, Chirenje ZM, Gaffikin L, Blumenthal PD, McGrath JA, Chipato T, Ngwalle S, Munjoma M, Shah KV (2000) HPV-based cervical cancer screening in a population at high risk for HIV infection. Int $J$ Cancer 85: 206-210

Xi LF, Toure P, Critchlow CW, Hawes SE, Dembele B, Sow PS, Kiviat NB (2003) Prevalence of specific types of human papillomavirus and cervical squamous intraepithelial lesions in consecutive, previously unscreened, West-African women over 35 years of age. Int J Cancer 103: 803-809 


\section{Appendix}

Combinations of human papillomavirus (HPV) types in 82 women with multiple infections in Ibadan, Nigeria are listed in Table 5.

Table 5 Combinations of human papillomavirus (HPV) types in 82 women

\begin{tabular}{|c|c|c|c|c|c|}
\hline HPV type & No & HPV type & No & HPV type & No \\
\hline $6,11,39$ & $\mathbf{I}^{\mathrm{a}}$ & $\mathbf{I} \mathbf{8}, 42, \mathbf{5 2}, 8 \mid, 83$ & $\mathbf{I}^{\mathrm{a}}$ & 39,58 & I \\
\hline $6,18,42$ & $\mathbf{I}^{\mathrm{a}}$ & $\mathbf{1 8 , 5 5}$ & I & 40,42 & I \\
\hline 6,35 & $\mathbf{I}^{\mathrm{a}}$ & $\mathbf{1 8 , 7 2}$ & I & $40, \mathbf{5 2}$ & I \\
\hline $6, \mathbf{3 5}, 40, \mathbf{5 6}, \mathbf{7 3}$ & I & 18,73 & I & 40,70 & I \\
\hline 6,43 & $1^{\mathrm{a}}$ & $|8,8|$ & $\mathbf{I}$ & 42,43 & I \\
\hline 6,66 & $\mathbf{I}^{\mathrm{a}}$ & $26,51,56$ & $\mathbf{I}$ & $42, \mathbf{4 5}, \mathbf{5 6}, \mathbf{5 8}$ & I \\
\hline||$, \mid \mathbf{8 , 5 8}$ & I & $31,35,43,52$ & I & 42,55 & I \\
\hline | |,3 | 34,42 & I & $31,35,52,8 \mid$ & $\mathbf{I}$ & 42,56 & I \\
\hline||$, \mathbf{3 5}, \mathbf{6 6}, 8 \mid$ & I & $31,35,70$ & I & $42, \mathbf{5 9}$ & I \\
\hline $16,26,58$ & I & $31,39,82$ & I & 42,72 & I \\
\hline $\mid$ 6,3 I,35,5 I,56 & $\mathbf{I}^{\mathrm{a}}$ & $\mathbf{3 1}, 42$ & $\mathbf{I}$ & 42,73 & I \\
\hline $\mid \mathbf{6 , 3} \mathbf{1 , 3 5 , 5 2 , 5 8 , 7 0 , 8 |}$ & I & $\mathbf{3} \mathbf{1}, 42,72,8 \mathbf{I}$ & I & 42,81 & I \\
\hline$|6,3|, 5 \mid$ & $\mathbf{I}$ & $\mathbf{3} \mathbf{1}, 42,81,83$ & I & $43, \mathbf{5 6}, 81$ & I \\
\hline $\mathbf{1 6}, 40,54, \mathbf{5 8 , 6 6}$ & I & $31,56,58$ & I & $45,52,8 \mid$ & I \\
\hline $\mathbf{1 6}, 42,72$ & I & 31,59 & I & 45,53 & I \\
\hline $16,42,83$ & $\mathbf{I}^{\mathrm{a}}$ & $\mathbf{3} \mathbf{1}, 8 \mathbf{1}$ & I & 45,81 & I \\
\hline 16,45 & I & $\mathbf{3 1} \mathbf{1} 8 \mathrm{I}, \mathrm{CP} 6 \mathrm{I} 08$ & I & $51,52,56$ & $\mathbf{I}^{\mathrm{a}}$ \\
\hline 16,52 & I & 33,45 & 2 & 51,66 & $\mathbf{I}^{\mathrm{a}}$ \\
\hline $16,52,54,66$ & I & 33,52 & I & $\mathbf{5 2 , 7 2}$ & I \\
\hline $\mathbf{1 6 , 5 2 , 5 5}$ & I & 33,56 & I & 56,58 & I \\
\hline I 6,58,66,70,83 & I & $\mathbf{3 5}, 42$ & $2 *$ & $\mathbf{5 6}, 81$ & I \\
\hline 16,66 & $\mathbf{I}^{\mathrm{a}}$ & $\mathbf{3 5}, 42,56,58$ & I & $\mathbf{5 6}, 83$ & I \\
\hline 16,83 & I & 35,45 & I & $\mathbf{5 8 , 7 2}$ & I \\
\hline$|8,3|$ & I & 35,51 & I & $\mathbf{5 8}, 81$ & $\mathbf{I}^{\mathrm{a}}$ \\
\hline $\mathbf{1 8 , 3} \mathbf{1}, 42$ & I & 35,66 & I & 68,81 & I \\
\hline$|8,35,5|$ & $\mathbf{I}^{\mathrm{a}}$ & 35,73 & I & 70,83 & I \\
\hline $18,35,56,68$ & I & 39,45 & $\mathbf{I}$ & & \\
\hline
\end{tabular}

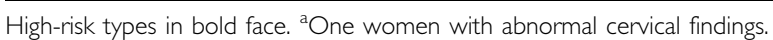

